Correction

\title{
Correction: Supuk, T.G., et al. Design, Development and Testing of a Low-Cost sEMG System and Its Use in Recording Muscle Activity in Human Gait. Sensors 2014, 14, 8235-8258
}

\section{Tamara Grujic Supuk *, Ana Kuzmanic Skelin and Maja Cic}

Faculty of Electrical Engineering, Mechanical Engineering and Naval Architecture,

Laboratory of Biomechanics and Automatic Control Systems, R. Boskovica 32, Split 21000, Croatia;

E-Mails: akuzmani@fesb.hr (A.K.S.); maja@fesb.hr (M.C.)

* Author to whom correspondence should be addressed; E-Mail: tamara.grujic@fesb.hr;

Tel.: +385-91-4305-642; Fax: +385-21-305-776.

Received: 25 July 2014 / Accepted: 4 August 2014 /

Published: 22 August 2014

The authors wish to make the following correction to this paper [1]. Due to an error Figure 15 was a duplicate of Figure 13, the former Figure 15 (labelled here as Previous Figure 15) should be replaced by the new version shown below (labeled here as New Figure 15):

Previous Figure 15. EMG signal (shown in Figure 13) filtered by wavelet method.

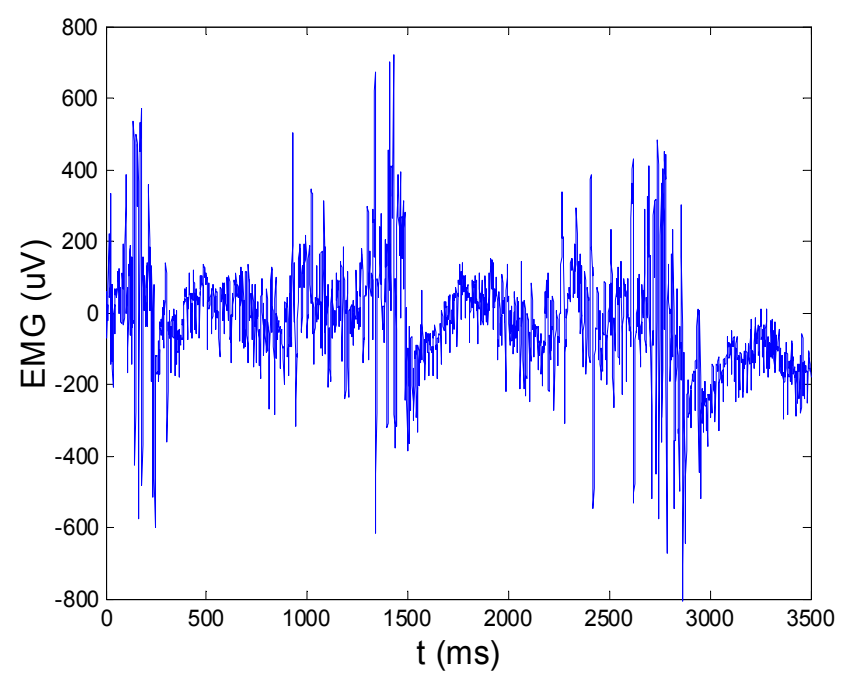


New Figure 15. EMG signal (shown in Figure 13) filtered by wavelet method.

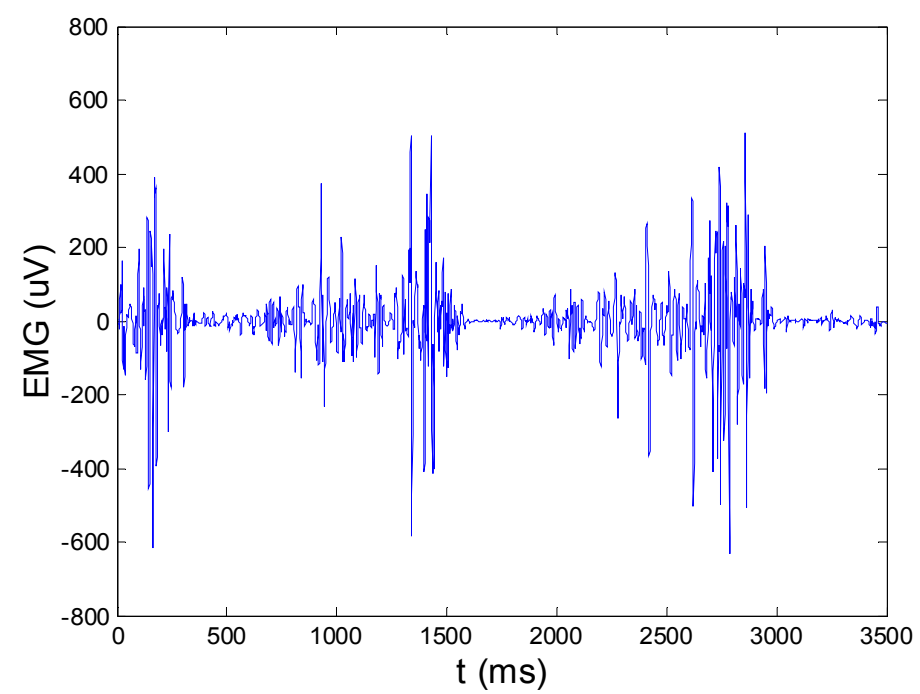

We apologize for any inconvenience caused to the readers.

\section{References}

1. Supuk, T.G.; Skelin, A.K.; Cic, M. Design, development and testing of a low-cost sEMG System and its use in recording muscle activity in human gait. Sensors 2014, 14, 8235-8258.

(C) 2014 by the authors; licensee MDPI, Basel, Switzerland. This article is an open access article distributed under the terms and conditions of the Creative Commons Attribution license (http://creativecommons.org/licenses/by/3.0/). 